University of Wollongong

Research Online

Faculty of Education - Papers (Archive)

Faculty of Arts, Social Sciences \& Humanities

2009

\title{
Relationships between fundamental movement skills and objectively measured physical activity in pre-school children
}

\author{
Dylan P. Cliff \\ University of Wollongong, dylanc@uow.edu.au \\ Anthony D. Okely \\ University of Wollongong, tokely@uow.edu.au \\ Lief Smith \\ Kim Mckeen \\ University of Wollongong, kmckeen@uow.edu.au
}

Follow this and additional works at: https://ro.uow.edu.au/edupapers

Part of the Education Commons

\section{Recommended Citation}

Cliff, Dylan P.; Okely, Anthony D.; Smith, Lief; and Mckeen, Kim: Relationships between fundamental movement skills and objectively measured physical activity in pre-school children 2009, 436-439. https://ro.uow.edu.au/edupapers/496 
4

5

6

7

8

9

10

RELATIONSHIPS BETWEEN FUNDAMENTAL MOVEMENT SKILLS AND OBJECTIVELY MEASURED PHYSICAL ACTIVITY IN PRESCHOOL CHILDREN

17


3 Gender differences in cross-sectional relationships between fundamental movement skill (FMS)

4 sub-domains (locomotor skills, object-control skills) and physical activity were examined in 5 preschool children. Forty-six 3- to 5-year-olds (25 boys) had their FMS video assessed (Test of

6 Gross Motor Development II) and their physical activity objectively monitored (Actigraph 7164 accelerometers). Among boys, object-control skills were associated with physical activity and explained $16.9 \%(p=0.024)$ and $13.7 \%(p=0.049)$ of the variance in percent of time in moderate-to-vigorous physical activity (MVPA) and total physical activity, respectively, after controlling for age, SES and $z$-BMI. Locomotor skills were inversely associated with physical activity among girls, and explained $19.2 \%(p=0.023)$ of the variance in percent of time in MVPA after controlling for confounders. Gender and FMS sub-domain may influence the relationship between FMS and physical activity in preschool children. 


\section{INTRODUCTION}

Physical activity is important for all children because of the associated benefits to physical, social and psychological health (31). Physical activity is often established during early childhood ( 2 to 5 years of age) $(14,22)$ and was recently identified as an early risk factor for child obesity (27). Current physical activity patterns of preschool children are cause for concern (26), and strategies to promote physical activity should be based on scientific evidence of the correlates and/or determinants of this behavior. A recent review of the correlates of physical activity in preschool children found a paucity of studies in the area and indicated that further quality research is required using validated physical activity measures (12). It is imperative, therefore, to better understand factors that may influence the physical activity habits of children during the preschool years.

One potential behavioral correlate of children's physical activity is their proficiency in fundamental movement skills (FMS). FMS are the building blocks for more complex motor skills and movement patterns and represent the underlying performance competency required for participation in many forms of physical activity (23). They are often divided into two domains: locomotor skills (e.g. run, hop and jump) and object-control skills (e.g. catch, throw and kick). The development of FMS proficiency is prominent in early childhood and primary school physical education curricula because of the importance FMS play in children's physical, cognitive and social development (23). Further, there is evidence that FMS relate to health outcomes in youth, with adolescents exhibiting greater FMS proficiency more likely to have higher cardio-respiratory fitness (19) and less-likely to be overweight (21) than their peers.

Studies investigating the relationship between FMS and physical activity in children and adolescents provide little consensus, with proficiency in FMS weakly $(13,20,34)$ to moderately 
1 (16) associated with physical activity and explaining as little as $3 \%$ (20) and as much as $25 \%$

2 (16) of the variance in habitual physical activity. Differences in the strength of the reported 3 associations can likely be explained by differences in the age groups examined as well as in the 4 measurement of physical activity (self-/parent-report vs. objective measurement) and FMS 5 (product-oriented vs. process-oriented assessment). The relationship between FMS and physical 6 activity, however, has been investigated rarely in preschool children. Fisher et al. (8) examined 7 the relationship between FMS and physical activity in nearly 400 Scottish children aged 3 to 5 . 8 They used an objective measure of physical activity and found a weak relationship with total 9 physical activity $(r=0.10)$ and with the percentage of time spent in moderate-to-vigorous 10 physical activity $(r=0.18)$. However the instrument used to assess actual competence was a 11 product-oriented battery, assessing skill outcome (motor abilities) rather than technique (processoriented). At lower or beginning levels of FMS proficiency, such as during the preschool years, products or outcomes of performance are often inconsistent and low, and thus may not adequately differentiate between individuals (4). Examining consistencies in movement patterns or technique through process-assessment, irrespective of inconsistent performance outcomes, can provide more useful information on FMS proficiency in young children (4). measured FMS proficiency and objectively measured habitual physical activity in preschool children, and to investigate if the relationship differed by gender and FMS sub-domain.

\section{METHODS}

\section{Participants and settings}


1 Data were collected as part of the Preschool Activity 'N' Dietary Adiposity (PANDA) study.

2 Participants were recruited from 11 randomly selected preschools within the city of Greater

3 Wollongong, (population $=0.3 \mathrm{M}$ ) in New South Wales, Australia. The sampling frame included

4 all early childhood centres $(n=130)$, from which 30 centres were randomly selected using a

5 computer-generated program, and the first 20 centres were approached. Data were collected from

6 April to September 2004 and the study was approved by the University of Wollongong Human

7 Research Ethics Committee. Parent/guardian consent was obtained for each participating child.

Anthropometry. Height was directly measured to the nearest millimetre, with portable stadiometers (Mentone Educational Centre, Victoria, Australia) using the stretch stature method. Weight was measured to the nearest $0.1 \mathrm{~kg}$ using portable calibrated Tanita HD646 electronic scales (Tanita Corporation of America Inc, Illinois, USA). Trained assessors took all measurements. Shoes and heavy clothing were removed prior to measurements. BMI was calculated from height and weight values, using the formula: weight $(\mathrm{kg}) / \mathrm{height}(\mathrm{m})^{2}$. Children's 
$1 z$-BMI was calculated based on their age and sex using lmsGrowth (Medical Research Council,

2 United Kingdom) and the UK reference curves (6).

4 Fundamental Movement Skill Proficiency. FMS proficiency was assessed using the Test of

5 Gross Motor Development-2 $2^{\text {nd }}$ Edition (TGMD-2) (32). The measure is comprised of locomotor

6 (run, gallop, hop, leap, horizontal jump, and slide) and object-control (t-ball strike, stationary

7 basketball dribble, catch, kick, overhand throw, and underhand roll) subtests, each assessing six

8 skills. The TGMD-2 assesses the skill performance process (skill components) rather than the

9 outcome or product of performance, and has established validity and reliability in this age group

10 (32). Prior to the testing of each skill, participants were given a visual demonstration of the skill

11 by the researcher using the correct technique, but were not told what components of the skill

12 were being assessed. Participants were then called individually to perform the skill twice. General encouragement but no verbal feedback on performance was given during or after the tests. All skills were video-recorded and later assessed by one trained assessor who also administered the tests. After viewing each trial, a number was placed in each of the boxes on the examiner record form that corresponded with each skill component. A " 1 " indicated that the component was present in the performance of the skill for that trial or, for continuous locomotor skills, was performed consistently throughout the trial (e.g. Run component 1: Arms move in opposition to legs, elbows bent); a " 0 " indicated the component was not present. After completing this procedure for each of the 12 skills, the scores of the two trials were totalled to obtain a raw score for each skill. Raw subtest scores were converted to age- and, for the objectcontrol sub-test, gender-adjusted standard scores using the appropriate conversion tables. Subtest standard scores were then summed and converted to calculate each child's Gross Motor 
Quotient (GMQ) (32).

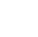

Physical Activity. Physical activity was objectively assessed using ActiGraph 7164 uniaxial accelerometers (MTI Health Services, Fort Walton Beach, FL, USA), which have established validity in preschoolers (30). Parents received an information sheet detailing monitoring protocol, as well as a monitoring log. Parents were asked to indicate on the log when the monitor was placed on their child, and when the monitor was taken off and the reason for doing so. Parents were instructed to keep the monitor on their child's right hip during waking hours, and to take the monitor off during aquatic activities. A seven-day monitoring period was used, and activity counts were accumulated and stored to the accelerometer over 1-minute epochs. Strings of " 0 " counts $\geq 20$ were considered periods of non-monitoring ( 7 ) and were removed from the total minutes monitored for a day during data reduction. Participant data were included in analyses if they recorded greater than 360 minutes ( 6 hours) of monitoring time each day, for at least three days (24).

The raw activity output, or accelerometer counts per minute (cpm) averaged over the monitoring period, was used in the analyses as a measure of total physical activity (mean cpm). In addition, counts were converted to minutes of sedentary behavior using the validated cut-point proposed by Reilly and colleagues $(<1100 \mathrm{cpm})(25)$. Minutes in moderate (MPA), vigorous (VPA), and moderate-to-vigorous physical activity (MVPA) were calculated using the Sirard et al. (30) definitions. The Sirard et al. MVPA definitions were validated against direct observation in pre-school children, and are age specific. According to these definitions, MPA was defined as: 2460 to 4920,3248 to 4936 , and 3564 to $5016 \mathrm{cpm}$, VPA was defined as: $>4920,>4936$, and $>5016 \mathrm{cpm}$, and MVPA was defined as: $>2460,>3248$ and, $>3564 \mathrm{cpm}$, for 3-, 4-, and 5-year- 
olds, respectively. To adjust for differences between children in the amount of monitoring time per day, total minutes spent at each activity intensity were divided by the total minutes monitored to calculate the percent of time spent in sedentary behavior, MPA, VPA, and MVPA.

(1)

\section{Statistical Analysis}

All analyses were conducted using SPSS version 16.0. Prior to analysis, normality of the data were assessed using a Kolmogrov-Smiranov test (with Lillefors' correction) and were visually inspected using histogram plots. Characteristics (age, SES, and $z$-BMI) of subjects in the current study sample (with complete FMS and physical activity data) were compared with those from the larger sample (with incomplete data) using independent samples $t$-tests or Mann-Whitney $U$ tests, where appropriate. Means and standard deviations were calculated for all normally distributed variables and median and interquartile ranges were calculated for those that were not normally distributed. Percent of time in MPA, and for boys, percent of time in MVPA were transformed (square root) to satisfy normality criteria. Independent samples $t$-tests were used to compare differences between boys and girls on normally distributed variables. Mann-Whitney $U$ tests were used where variables were not normally distributed.

As research in older children has reported gender differences in associations between FMS and physical activity $(13,16)$, analyses of association were conducted with the sample stratified by gender. Pearson product-moment correlations were performed to examine relationships where variables were normally distributed, and Spearmen rank-order correlations were carried out where variables were not normally distributed. Sex-specific hierarchical regression models were then conducted to establish whether locomotor and/or object-control standard scores accounted for a significant amount of incremental variance in percent of time in 
1 MVPA and total physical activity (mean cpm), after controlling for age, SES, and child $z$-BMI.

Regression models were run only where FMS sub-domains were correlated to physical activity outcomes $(p<0.10)$. Statistical significance was set at $p<0.05$ for all other analyses.

\section{RESULTS}

Of the 20 centres originally approached, 14 declined participation. Two centres were able to be replaced from the 10 additional centres that were randomly selected and an additional three were able to be replaced from an extra list of 10 randomly selected centres. Replacements were unable to be found for nine of these centres within the study timeframe. In all, 33 centres were approached and 11 agreed to participate (response rate $=33 \%$ ). The majority of the centres declined to participate because they did not feel comfortable with research being conducted in their setting. The response rate for children was 58\% (144/249). Six children were either absent from the day of testing or refused testing, leaving 138 children who completed anthropometric assessments.

Time and budget restrictions prevented one school $(n=19)$ from completing FMS assessments. Five children with anthropometric data were $<3$ y and did not have their FMS assessed because the TGMD-2 has not been validated in children $<3$ y of age. Further, seven children who completed anthropometric assessments chose not to participate in the FMS tests and five children who began the FMS assessments did not complete the battery of tests. As such, complete FMS data were collected from 102 children. Of those, 46 also had complete physical activity data and these participants comprised the current study sample. Physical activity data were not available in other study participants due to: non-consent to physical activity monitoring ( $n=27)$, data not meeting inclusion criteria $(n=22)$, or monitor malfunction $(n=7)$. The sample 
for the current study did not differ from the larger recruited sample in regards to age, SES or $z$ BMI (all $p>0.05)$.

The sample consisted of 25 boys and 21 girls [mean age $=4.3 \pm 0.7 \mathrm{y}$, mean height $=$ $105.2 \pm 6.1 \mathrm{~cm}$, median BMI $=15.9(15.4,16.8) \mathrm{kg} / \mathrm{m}^{2}$, and median $z-\mathrm{BMI}=0.23(-0.13,0.78)$ units], who were of slightly higher SES according to their IRSD score [median $=990.2(969.7$, 999.8)] than the greater City of Wollongong $($ IRSD = 980.9) $(1)$. The mean duration of physical activity monitoring was $4.1 \pm 1.0$ days and $641.0 \pm 95.9$ minutes/day, and the sample spent approximately $23.0(15.0,44.2)$ minutes/day in MVPA. Participating boys and girls did not differ on demographic, anthropometric or physical activity outcomes (all $p>0.05$ ) (Table 1). Girls' mean locomotor subtest raw score was higher than boys' (26.4 vs. 20.2, $p=0.009$ ), although no differences were found for the object control raw score $(22.0$ vs. 20.6, $p=0.467)$. As the objectcontrol score standard score is adjusted for gender (32), girls scored higher than boys on both the locomotor $(9.9$ vs. $7.9, p=0.003)$ and object-control standard scores $(10.1$ vs. $8.6, p=0.026)$, and subsequently the GMQ (99.7 vs. $88.2, p<0.001)$.

For both boys and girls, z-BMI and SES were not found to relate to physical activity outcomes (Table 2). Age, however, was negatively associated with percent of time in MPA for boys $(\mathrm{r}=-0.48, p=0.015)$ and girls $(\mathrm{r}=-0.47, p=0.032)$. Amongst boys, locomotor standard score was marginally related to percent of time in MVPA $(r=0.34, p=0.098)$; object-control standard score was related to percent of time in MPA $(r=0.52, p=0.008)$ and MVPA $(r=0.48$, $p=0.015)$; and was marginally related to total physical activity $(\mathrm{r}=0.37, p=0.070)$. Subsequently, GMQ was marginally related to percent of time in MVPA ( $\mathrm{r}=0.38, p=0.061)$ and total physical activity in boys $(\mathrm{r}=0.39, p=0.056)$, and was related to their percent of time in VPA $(r=0.46, p=0.020)$. For girls, object-control standard score was not related to physical 

.

activity outcomes. Both locomotor standard score and GMQ were negatively related to percent of time in MPA $(r=-0.52, p=0.015$ and $r=-0.44, p=0.047$, respectively $)$ and MVPA $(r=-$ $0.50, p=0.022$ and $\mathrm{r}=0.46, p=0.038$, respectively) for girls.

Stepwise multiple hierarchical regression analysis indicated that object-control standard score was independently associated with boy's percent of time in MVPA and explained an additional $16.9 \%$ of the variance after controlling for age, SES, and $z$-BMI (Table 3). In contrast, the model for girls indicated that locomotor standard score was inversely associated with percent of time in MVPA and explained an additional 19.2\% of the variance after accounting for background (confounding) variables. Among boys, object-control skills were independently associated with total physical activity and explained $13.7 \%$ of the variance after accounting for age, SES, and $z$-BMI.

In this study sample and setting, boys and girls were found to be equally proficient at performing object control skills, although girls scored higher than boys for locomotor skills and subsequently for the gross motor quotient. FMS were positively correlated with objectively measured habitual physical activity in preschool boys and negatively correlated to habitual physical activity in preschool girls. For boys, object control skills held stronger positive associations with physical activity outcomes (percent of time in MPA and MVPA, and total physical activity) than locomotor skills. While for girls, locomotor skills held stronger negative associations with habitual physical activity outcomes (percent of time in MPA and MVPA) than object-control skills. 
The theoretical basis explaining the mechanisms of a positive association between FMS and physical activity, as was found amongst boys in the current study, purports that proficiency in movement skills provides the behavioral competency required for participation in a variety of physical activities (23), and may influence other determinants of behaviour, such as perceptions of competence (2) and positive affect (e.g. enjoyment or satisfaction) (18). Without the prerequisite movement competence, children may opt out of opportunities for physical activity or may have preference for more sedentary pursuits (18).

This explanation, however, assumes that FMS are the cause rather than the consequence of physical activity, which cannot be inferred from the cross-sectional analyses reported in previous studies in the area and in the current examination. Greater physical activity opportunities might also provide the context to improve FMS proficiency, which is important to consider when examining early childhood populations where FMS and motor coordination are at the earliest stages of development (10). Longitudinal (15) and experimental studies $(5,28)$ have generally been unable to provide evidence of a causal relationship between FMS and physical activity in youth. Recent evidence in older children, however, indicates that movement competency in childhood predicts self-reported physical activity in adolescence (3), suggesting that, at some stage of child and adolescent development, proficiency in movement skills plays a causal role in determining physical activity behavior.

Studies comparing the relationship between FMS/motor proficiency and physical activity amongst boys and girls provide inconsistent conclusions; some indicate similar relationships (8, $33,34)$ while others suggest a stronger relationship amongst boys $(13,16)$. Comparisons between studies are made difficult by methodological heterogeneity, particularly in FMS measures. Using the same measures as in the current study but in an overweight sample, Morgan et al. (16) also 
found the positive relationship between FMS and physical activity to be stronger among boys. FMS proficiency possibly plays a more influential role in popular forms of physical activities participated in by boys (17), whereas other psychosocial or environmental factors might be more strongly related to physical activity in girls (12). Despite using a validated age-appropriate FMS measurement battery that assesses a wide range of both locomotor and object control skills, the stronger relationship found in boys could also be due in part to the particular FMS measured in the current study. That is, proficiency in movement skills other than those assessed in the current study, such as balance and movement to a rhythm (17), may be more strongly associated with physical activity in young girls. Likewise, the stronger positive associations between FMS and physical activity found for boys in the current study and that by Morgan and colleagues (16), compared with previous examinations $(8,34)$, might be due to the ability of the movement skills measured to more closely represent the competencies used in popular physical activities for boys, along with the method of measurement (product-assessment vs. process-assessment).

Partitioning FMS into sub-domains in the current study and others $(13,16)$, has suggested that object-control skills relate most strongly to boys' habitual physical activity, and this is plausible considering their role in popular activities participated in by elementary/primary school aged boys (eg. soccer, cricket, basketball, Australian football) (17). The negative association found in the current study between locomotor skills and physical activity for girls is more difficult to explain considering that, in older children, this sub-domain of skills has been shown to relate positively and more strongly to physical activity outcomes $(13,16)$. One study in preschool children indicated that no association or a weak relationship might be more likely in this age group (8). Analyses by Williams and colleagues (33), however, suggested that locomotor skills might relate more strongly to objectively measured physical activity than object control 
1 skills in 4-year-olds. Like the current study, Williams et al. (33) assessed a comprehensive range

of movement skills, but in contrast, their findings did not indicate gender differences in the relationship between motor proficiency and physical activity. The generalizability of our finding for girls should be investigated in larger cross-sectional studies as the limited sample in this preliminary investigation may have influenced the results. Likewise, it is possible that this finding could be the consequence of multiple correlations, which may have created alpha inflation and resulted in Type 1 error.

The use of an objective measure of physical activity and video assessments of FMS using a validated, process-oriented measure, were methods that reduced measurement bias in the current study. Further, both the physical activity and FMS measures were able to differentiate behaviors into meaningful sub-categories, allowing for a unique examination of the relationship between these outcomes in a population where our understanding of the correlates of physical activity is limited (12). Analyses also controlled for confounding variables, in order to examine the unique variance in habitual physical activity explained by FMS sub-domains.

Physical activity assessments in the current study may have been limited by the use of a uniaxial accelerometer, a 1-minute epoch, and the inclusion criteria of at least 3 days and 360 minutes/day of usable data. Although uniaxial accelerometers set to collect data at 1-minute epochs may theoretically underestimate the multi-directional and sporadic physical activity behavior of preschool children, the magnitude of the effects on estimates of physical activity require further examination (29). It is plausible that the epoch used in this study could potentially underestimate time spent in VPA and MVPA (29). The physical activity data inclusion criteria used in the current study, while possibly not optimal, has been shown to provide adequately reliable estimates of habitual physical activity in this age group (24). The assessments may have 
underestimated children's true activity levels because accelerometers are insensitive to some physical activities, such as bicycle riding, and the particular accelerometer used was not waterproof, and consequently could not capture aquatic activities. Furthermore, as physical activity was assessed during autumn, winter, and spring in the southern hemisphere, the data may also have been confounded by seasonal and weather-related variations. Research in this age group, however, suggests that the effects of both weather and season on objectively-measured physical activity might be small and not biologically meaningful (9). Findings from studies in older children suggest that the association between physical activity and motor development might be most relevant at the extremes of the distribution (34). For example, it may only be individuals at the highest quartile of motor skills that are the most physically active rather than a linear association. The small sample size meant that there was inadequate power to examine such relationships in this study. The generalizability of the findings from this preliminary investigation require investigation in larger cross-sectional studies, as the small sample and missing data may have influenced the associations between outcomes for both boys and girls. Likewise, longitudinal analyses are required, beginning in the preschool years, to better examine causal associations between FMS and physical activity in children. Future studies that use the preschool as the sampling unit for participants should be adequately powered to adjust analyses for clustering (11); that is the likelihood that children from the same school are more similar to each other than to children from other schools in terms of their movement skill proficiency and physical activity patterns. Our inability to control for such effects in the current study is recognized as a limitation that should be considered when interpreting the findings.

This study indicates that the relationship between FMS and physical activity in preschool children may differ by gender, by movement skill sub-domain, and by physical activity intensity. 
1 The relationship, at least for boys, might be stronger than has previously been reported in this

2 population. Longitudinal studies are warranted that are adequately powered to stratify by gender

3 and that can examine sub-categories of FMS, to better understand the causal nature of the

4 relationship and to provide a stronger rationale for the development of FMS and the promotion

5 of physical activity in early childhood.

6

7

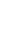

\section{ACKNOWLEDGEMENTS}

We wish to thank the preschools, children and their parents; Alsison Crowshaw and Karen Mickle for their assistance with data collection; and Lauren Puglisi for her assistance with manuscript preparation. This study was funded by a University of Wollongong Strategic Research Development Grant. REFERENCES

1. Australian Bureau of Statistics. Information paper: Socio-economic indexes for areas, Australia, 2001: Catalogue No. 2039. Canberra, Australia: Australian Bureau of Statistics; 2003. 2. Barnett, L.M., P.J. Morgan, E. van Beurden, J.R. Beard. Perceived sports competence mediates the relationship between childhood motor skill proficiency and adolescent physical activity and fitness: a longitudinal assessment. Int. J. Beh. Nutr. Phys. Act. 5(40): doi: 10.1186/479-5868-5-40, 2008.

3. Barnett, L.M., E. van Beurden, P.J. Morgan, L. Brooks, J.R. Beard. Childhood motor skill proficiency as a predictor of adolescent physical activity. J. Adolesc. Health. doi: 10.1016/j.jadohealth.2008.07.004, 2008. 
1 4. Burton, A.W., D.E. Miller. Movement Skill Assessment. Champaign, IL: Human Kinetics, 21998.

3 5. Cliff, D.P., A. Wilson, A.D. Okely, K. Mickle, J.R. Steele. Feasibility of SHARK: A

4 physical activity skill-development program for overweight and obese children. J. Sci. Med. 5 Sport. 10(4): 263-7, 2007.

66 Cole, T.J., J.V. Freeman, M.A. Preece. Body mass index references curves for the UK, 7 1990. Arch. Dis. Child. 73: 25-9, 1995.

87 Esliger, D.W., J.L. Copeland, J.D. Barnes, M.S. Tremblay. Standardizing and optimizing 9 the use of accelerometer data for free-living physical activity monitoring. J. Phys. Act. Health. 3: $10 \quad 366-83,2005$.

118 Fisher, A., J.J. Reilly, L.A. Kelly, C. Montgomery, A. Williamson, J.Y. Paton, et al. 12 Fundamental movement skills and habitual physical activity in young children. Med. Sci. Sports Exerc. 37(4): 684-8, 2005.

9. Fisher, A., J.J. Reilly, C. Montgomery, L.A. Kelly, A. Williamson, D.M. Jackson, et al. Seasonality in physical activity and sedentary behaviour in young children. Ped. Exerc. Sci. 17(1): 31-40, 2005.

10. Gallahue, D.L., J.C. Ozmun. Understanding Motor Development: Infants, Children, Adolescents, Adults. 5th ed. New York: McGraw-Hill, 2002. 11. Hayen, A. Clustered data in sports research. J. Sci. Med. Sport. 9: 165-8, 2006. 12. Hinkley, T., D. Crawford, J. Salmon, A. Okely, K. Hesketh. Preschool children and 21 physical activity: a review of correlates. Am. J. Prev. Med. 34(5): 435-41, 2008. 
1 13. Hume, C., A. Okely, S. Bagley, A. Telford, M. Booth, D. Crawford, et al. Does weight

2 status influence associations between children's fundamental movement skills and physical

3 activity? Res. Q. Exerc. Sport. 79(2): 158-65, 2008.

$4 \quad$ 14. Jackson, D.M., J.J. Reilly, L.A. Kelly, C. Montgomery, S. Grant, J.Y. Paton. Objectively 5 measured physical activity in a representative sample of 3- to 4-year-old children. Obesity. 11(3):

$6 \quad 420-5,2003$.

7 15. McKenzie, T.L., J.F. Sallis, S.L. Broyles, M.M. Zive, P.R. Nader, C.C. Berry, et al.

8 Childhood movement skills: predictors of physical activity in Anglo American and Mexican

$9 \quad$ American Adolescents? Res. Q. Exerc. Sport. 73(3): 238-44, 2002.

10 16. Morgan, P.J., A.D. Okely, D.P. Cliff, R.A. Jones, L. Baur. Correlates of objectively

11 measured physical activity in obese children. Obesity. 16: 2364-2641, 2008.

12 17. Okely, A.D., J.A. Wright. The gender bias in fundamental movement skills tests: a new agenda! The Australian Association for Research in Education; 1997; Brisbane, Australia; 1997. p. http://www.aare.edu.au/97pap/okela137.htm. 18. Okely, A.D., M.L. Booth. Relationship of enjoyment of physical activity and preferred activities to fundamental movement skill proficiency in young children. Int. J. Beh. Med. 7(Suppl. 1): 151, 2000.

19. Okely, A.D., M.L. Booth, J.W. Patterson. Relationship of physical activity to fundamental movement skills among adolescents. Med. Sci. Sports Exerc. 33: 1899-904, 2001. 20. Okely, A.D., M.L. Booth, J.W. Patterson. Relationship of cardiorespiratory endurance to 21 fundamental movement skill proficiency among adolescents. Ped. Exerc. Sci. 13: 380-91, 2001. 
1 21. Okely, A.D., M.L. Booth, T. Chey. Relationships between body composition and

2 fundamental movement skills among children and adolescents. Res. Q. Exerc. Sport. 75: 238-48,

32004.

4 22. Pate, R.R., T. Baranowski, M. Dowda, S. Trost. Tracking of physical activity in young 5 children. Med. Sci. Sports Exerc. 28: 92-6, 1996.

6 23. Payne, G., D. Isaacs. Human Motor Development: A Lifespan Approach. 3rd ed. London:

$7 \quad$ Mayfield Publishing Company, 1995.

8 24. Penpraze, V., J.J. Reilly, C.M. MacLean, C. Montgomery, L.A. Kelly, J.Y. Paton, et al.

9 Monitoring of physical activity in young children: how much is enough? Ped. Exerc. Sci. 18:

$10 \quad 483-91,2006$.

11 25. Reilly, J.J., J. Coyle, L.A. Kelly, G. Burke, S. Grant, J.Y. Paton. An objective method for 12 measurement of sedentary behaviour in 3- to 4-year olds. Obes. Res. 11: 1155-8, 2003. 26. Reilly, J.J., D.M. Jackson, C. Montgomery, L.A. Kelly, C. Slater, S. Grant, et al. Total energy expenditure and physical activity in young Scottish children: mixed longitudinal study. Lancet. 363: 211-2, 2004.

27. Reilly, J.J., J. Armstrong, A.R. Dorosty, P.M. Emmett, A. Ness, I. Rogers, et al. Early life risk factors for obesity in childhood: cohort study. BMJ. 330: 1357, 2005.

28. Reilly, J.J., L. Kelly, C. Montgomery, A. Williamson, A. Fisher, J.H. McColl, et al. Physical activity to prevent obesity in young children: cluster randomised controlled trial. $B M J$. 333: 1041-3, 2006.

29. Reilly, J.J., V. Penpraze, J. Hislop, G. Davies, S. Grant, J.Y. Paton. Objective measurement of physical activity and sedentary behaviour: review with new data. Arch. Dis. Child. 93(7): 614-9, 2008. 
1 30. Sirard, J.R., S.G. Trost, K.A. Pfeiffer, M. Dowda, R.R. Pate. Calibration and evaluation

2 of an objective measure of physical activity in preschool children. J. Phys. Act. Health. 3: 345-

$357,2005$.

4 31. Strong, W.B., R.M. Malina, C.J.R. Blimkie, S.R. Daniels, R.K. Dishman, B. Gutin, et al.

5 Evidence based physical activity for school-age youth. J. Pediatrics. 146: 732-7, 2005.

6 32. Ulrich, D.A. Test of Gross Motor Development. 2nd ed. Austin, TX: PRO-ED, 2000.

7 33. Williams, H., K. Pfeiffer, J. O'Neill, M. Dowda, K. McIver, W. Brown, et al. Motor skill

8 performance and physical activity in preschool children. Obesity. 16(6): 1421-6, 2008.

9 34. Wrotniak, B.H., L.H. Epstein, J.M. Dorn, K.E. Jones, V.A. Kondilis. The relationship 10 between motor proficiency and physical activity in children. Pediatrics. 118: 1758-65, 2006. 
1 Table 1 Demographic, anthropometric, physical activity and fundamental movement skill

descriptive statistics for boys and girls

\begin{tabular}{|c|c|c|c|c|}
\hline Variable & $\begin{array}{c}\text { Boys } \\
(n=25)\end{array}$ & $\begin{array}{c}\text { Girls } \\
(n=21)\end{array}$ & $t / z$ & $p$ \\
\hline \multicolumn{5}{|l|}{ Demographic } \\
\hline Age (years), mean $\pm \mathrm{SD}$ & $4.24 \pm 0.69$ & $4.35 \pm 0.64$ & -0.57 & 0.570 \\
\hline SES, median (IQ range) & $993.2(946.8,999.8)$ & $987.4(977.4,1005.6)$ & -0.31 & 0.755 \\
\hline \multicolumn{5}{|l|}{ Anthropometry } \\
\hline Height $(\mathrm{cm})$, mean \pm SD & $105.1 \pm 5.7$ & $105.3 \pm 6.6$ & -0.11 & 0.910 \\
\hline $\begin{array}{l}\text { Weight (kg), median (IQ } \\
\text { range) }\end{array}$ & $17.7(16.1,18.7)$ & $17.3(15.6,20.1)$ & -0.20 & 0.843 \\
\hline $\begin{array}{l}\text { BMI }\left(\mathrm{kg} / \mathrm{m}^{2}\right) \text {, median (IQ } \\
\text { range) }\end{array}$ & $15.86(15.09,16.64)$ & $16.03(15.59,17.14)$ & -0.61 & 0.544 \\
\hline$z$-BMI, median (IQ range) & $0.21(-0.54,0.60)$ & $0.25(-0.09,0.99)$ & -0.87 & 0.384 \\
\hline \multicolumn{5}{|l|}{ Physical Activity } \\
\hline $\begin{array}{l}\text { Mean accelerometer CPM, } \\
\text { mean } \pm \text { SD }\end{array}$ & $882.53 \pm 264.48$ & $864.49 \pm 159.13$ & 0.29 & 0.777 \\
\hline $\begin{array}{l}\% \text { of time in sedentary } \\
\text { behavior, mean } \pm \mathrm{SD}\end{array}$ & $81.82 \pm 6.66$ & $83.20 \pm 3.50$ & -0.90 & 0.373 \\
\hline $\begin{array}{l}\% \text { of time in MPA, mean } \pm \\
\text { SD }\end{array}$ & $2.57(1.72,4.95)$ & $2.46(1.40,3.61)$ & -1.33 & 0.182 \\
\hline $\begin{array}{l}\% \text { of time in VPA, mean } \pm \\
\text { SD }\end{array}$ & $1.63 \pm 1.28$ & $1.54 \pm 3.50$ & 0.28 & 0.781 \\
\hline $\begin{array}{l}\% \text { of time in MVPA, median } \\
\text { (IQ range) }\end{array}$ & $3.37(2.23,7.85)$ & $4.00(2.25,5.61)$ & -0.88 & 0.378 \\
\hline $\begin{array}{l}\text { MVPA (mins/day), median } \\
\text { (IQ range) }\end{array}$ & $23.25(14.00,57.75)$ & $22.67(15.00,35.75)$ & -1.05 & 0.295 \\
\hline \multicolumn{5}{|l|}{ Fundamental Movement Skills } \\
\hline $\begin{array}{l}\text { Locomotor raw score (range: } \\
0-48) \text {, mean } \pm \mathrm{SD}\end{array}$ & $20.24 \pm 7.72$ & $26.38 \pm 7.5$ & -2.72 & 0.009 \\
\hline $\begin{array}{l}\text { Locomotor standard score } \\
\text { (range: } 1-20), \text { mean } \pm \text { SD }\end{array}$ & $7.92 \pm 2.12$ & $9.86 \pm 2.08$ & -3.11 & 0.003 \\
\hline $\begin{array}{l}\text { Object-control raw score } \\
\text { (range: } 0-48), \text { mean } \pm \mathrm{SD}\end{array}$ & $20.60 \pm 6.14$ & $22.0 \pm 6.8$ & -0.73 & 0.467 \\
\hline $\begin{array}{l}\text { Object-control standard } \\
\text { score (range: } 1-20) \text {, mean } \pm \\
\text { SD }\end{array}$ & $8.60 \pm 2.18$ & $10.05 \pm 2.08$ & -2.31 & 0.026 \\
\hline $\begin{array}{l}\text { Gross Motor Quotient } \\
\text { (range: } 64-160) \text {, mean } \pm \mathrm{SD}\end{array}$ & $88.24 \pm 10.13$ & $99.71 \pm 10.47$ & -3.77 & $<0.001$ \\
\hline
\end{tabular}

Note. SES, Socioeconomic Status; BMI, body mass index; CPM, counts per minute; MPA, moderate physical activity; VPA, vigorous physical activity, MVPA, moderate-to-vigorous physical activity.

Normal data are presented as mean $\pm \mathrm{SD}$ and independent samples $t$-test $(t, p)$; Non-normal data are presented as median (interquartile range) and Mann Whitney $U$ test $(z, p)$. 


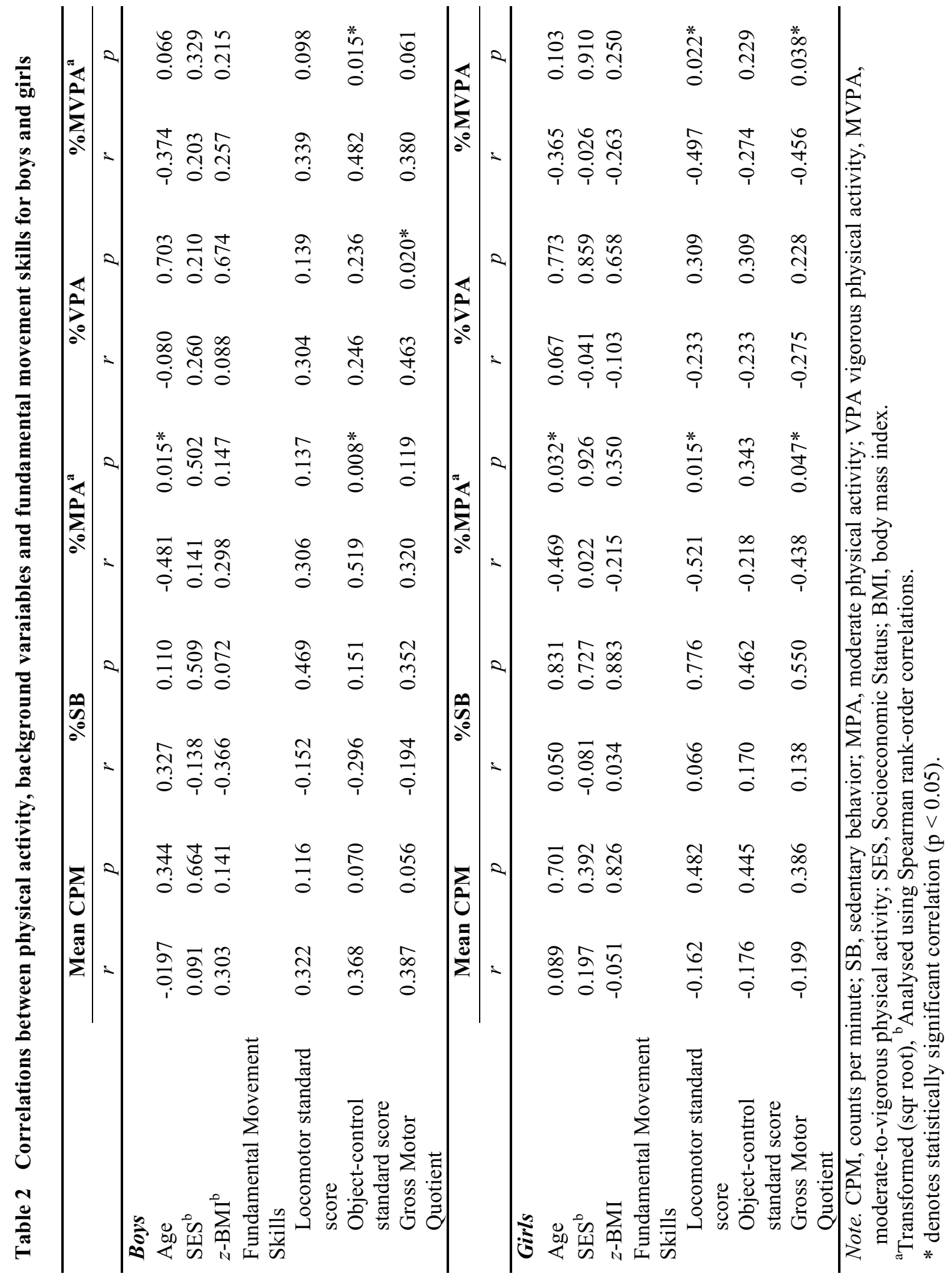




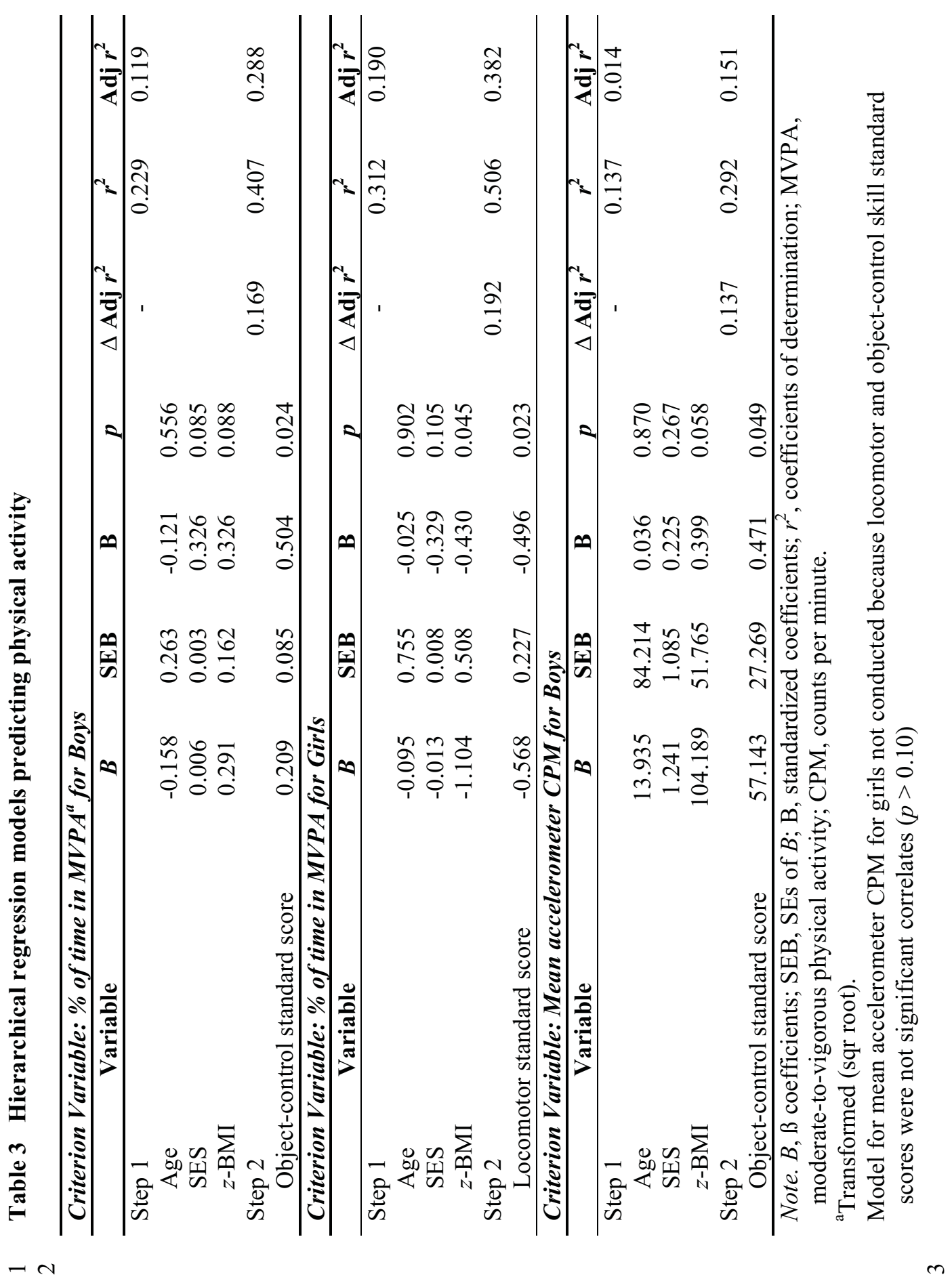

